\title{
Introduction of pneumococcal conjugate vaccine in Universal Immunization Programme in India: A step toward realizing sustainable development goals
}

\section{A Bashar \\ From Senior Resident, Department of Community Medicine, School of Public Health, Postgraduate Institute of Medical Education and Research, Chandigarh, India}

Correspondence to: Dr. M A Bashar, R. No. 125, School of Public Health, Postgraduate Institute of Medical Education and Research, Chandigarh - 160 012, India. E-mail: dr.bashartheultimate86@gmail.com

Received - 02 March $2019 \quad$ Initial Review - 21 March 2019

Accepted - 20 July 2019

$\mathrm{V}$ accination is one of the public health measures that have the greatest impact on the reduction of the burden from infectious diseases and associated mortality, especially in children. It is estimated that, each year worldwide, vaccines prevent up to 3 million deaths [1,2]. Immunization is one of the most cost-effective interventions to save and prolong life [3]. Expanded Programme on Immunization (EPI), which was launched by the World Health Organization in the year 1974, aimed to protect all the children of the world from six vaccinepreventable diseases - Bacille Calmette-Guérin vaccine for tuberculosis, diphtheria-pertussis-tetanus vaccine, and oral polio and measles vaccine. Hepatitis B vaccine was introduced later in the 1980s [4].

In India, EPI was flagged off in 1978, mainly in the urban areas, for immunizing children $<1$ year of age group. Through the subsequent years, more vaccines were included in the EPI program, for example, oral polio vaccine in 1979 and the vaccine to immunize pregnant mothers with tetanus toxoid vaccine in 1983. In 1985, the program was renamed as the Universal Immunization Program (UIP) focusing mainly on infants and pregnant mothers. Measles vaccine was included in the program in 1990 and the program was expanded to spread across the country [5]. India included the $2^{\text {nd }}$ dose of measles vaccine in the National Immunization Program in 2010. Hepatitis B vaccination was included in UIP in 2002-2003, and in 2011, it covered whole of India.

With the financial support from global alliance for vaccine and immunization, Indian government included Pentavac vaccine as a pilot project in few selected states in 2011, which was later scaled up in all states under the UIP by 2015 [6]. According to the recommendation of National Technical Advisory Group of India, Government of India included four new vaccines for polio (injectable), Rotavirus, rubella, and Japanese encephalitis (179 districts) in the UIP for whole India [7]. The UIP aims to vaccinate 26 million newborns and 30 million pregnant mothers annually for vaccines covered under the program [8]. More than 9 million immunization sessions are conducted annually with nearly 27,000 cold chain points across the country [8]. Disease burden, safety, efficacy, cost-effectiveness, and operational requirements of the vaccination program are some of the important factors considered before including a vaccine in the national UIP [6].
The Government of India has recently decided to include pneumococcal conjugate vaccine (PCV) in UIP. For the $1^{\text {st }}$ time, millions of children in India would be receiving protection for free against the leading cause of pneumonia, which kills more underfive children than any other infectious disease [9] Until now, PCV was only available in the private sector in India, putting it beyond the reach of most of the population. By making it available under the UIP, the Government of India has ensured equitable access to the underprivileged and underserved.

PCV was launched by the Union Health Minister, Shri JP Nadda on May 13, 2017, at Mandi, Himachal Pradesh [9]. With its phased introduction, nearly 2.1 million children in Himachal Pradesh (all 12 districts), parts of Bihar (17 of 38 districts), and Uttar Pradesh ( 6 of 75 districts) have been vaccinated with PCV in the $1^{\text {st }}$ year. This was followed by introduction in Madhya Pradesh and Rajasthan next year, and eventually, coverage will be expanded across the entire country in a phased manner, in the coming years. With the introduction of PCV in UIP, protection will be offered to the children from 12 diseases (tuberculosis, polio, diphtheria, pertussis, tetanus, hepatitis $\mathrm{B}$, measles, Haemophilus influenzae b, Rotavirus diarrhea, Japanese encephalitis (in endemic states), rubella, and pneumococcal disease) [10].

Introduction of PCV in the UIP will reduce child deaths from pneumococcal pneumonia. Further, it would also reduce the number of children being hospitalized for pneumonia and, therefore, reduce the economic burden on families and the health cost burden on the country. As the schedule of pentavalent and pneumococcal vaccines is same $(6,10$, and 14 weeks) in the present vaccination schedule under UIP, the introduction of this new vaccine will not affect the frequency of visit to health facility, which, in turn, will not affect the cost and coverage of the program.

Pneumonia is the single largest infectious cause of death among under-five children worldwide, accounting for about 0.92 million deaths every year. It is estimated that 1 in 6 deaths in under-five children was due to pneumonia in 2015 [11]. More than $80 \%$ of deaths associated with pneumonia occur in children during the first 2 years of life [12]. Pneumococcal disease is also the number one vaccine-preventable cause of death in children under five, globally and in India [9]. Pneumococcal pneumonia, in particular, is a major public health concern for children globally. 
This infection accounts for $18 \%$ of all severe pneumonia cases and $33 \%$ of all pneumonia deaths worldwide $[12,13]$.

India has a pneumonia mortality rate of 7/1000 live births [14]. Similar to the global scenario, pneumonia due to Streptococcus pneumoniae (pneumococcal pneumonia) is responsible for a large portion of pneumonia episodes and deaths in India. In 2010, 3.6 million episodes of severe pneumonia and 0.35 million allcause pneumonia deaths occurred in children under the age of 5 years in India. Among those, 0.56 million episodes (16\%) of severe pneumonia and 0.10 million deaths (30\%), respectively, were caused by pneumococcal pneumonia [12].

Introduction of PCV in UIP in India is a right step toward achieving one of the important targets of the sustainable development goals, i.e., by 2030 , to end the preventable deaths of newborns and children under 5 years of age and to reduce underfive mortality to as low as $25 / 1000$ live births [15].

\section{REFERENCES}

1. Global Alliance for Vaccines and Immunization. Fact Sheet No. 169. World Health Organization Media Centre; 2011.

2. Ehreth J. The economics of vaccination from a global perspective: Present and future 2-3 december, 2004, vaccines: All things considered, San Francisco, CA, USA. Expert Rev Vaccines 2005;4:19-21.

3. Ozawa S, Clark S, Portnoy A, Grewal S, Brenzel L, Walker DG, et al. Return on investment from childhood immunization in low and middle-income countries, 2011-20. Health Aff (Millwood) 2016;35:199-207.

4. Available from: https://www.who.int/immunization/programmes_systems/ supply_chain/benefits_of_immunization/en. [Last accessed on 2019 Jan 15].

5. Khere A, Gupta A, Gogia H, Rao S. India's National Immunization Programme. New Delhi: Seminar Publication; 2012. Available from: http:// www.india-seminar.com/2012/631/631_ajay_khera_et_at html. [Last cited on 2018 Aug 05].

6. Lahariya C. A brief history of vaccines and amp; vaccination in India. Indian J Med Res 2014;139:491-511.

7. Datta J. Four Vaccines Added to India's Immunization Programme. The
Hindu News Paper; 2014.

8. National Health Mission. Ministry of Health and Family Welfare, Government of India. Routine Immunization. Available from: http://www. nhm.gov.in/nrhm-components/rmnch-a/immunization/immunization.html. [Last accessed on 2017 May 22].

9. Immunization Technical Support Unit (ITSU). The Power of Vaccines: Protecting India's Future. Available from: http://www.jhsph.edu/research/ centers-and-institutes/ivac/resources/factsheets/The $\% 20$ Power $\% 20$ of $\% 20$ Vaccines\%20Brochure.pdf. [Last accessed on 2019 Jan 22].

10. Press Information Bureau. Government of India. Ministry of Health and Family Welfare. Shri J P Nadda launches Pneumococcal Conjugate Vaccine (PCV) Under Universal Immunization Programme (UIP). Available from: http://www.pib.nic.in/newsite/PrintRelease.aspx?relid=161763. [Last accessed on 2019 Jan 22].

11. Liu L, Oza S, Hogan D, Perin J, Rudan I, Lawn JE, et al. Global, regional, and national causes of child mortality in 2000-13, with projections to inform post-2015 priorities: An updated systematic analysis. Lancet 2015;385:430-40.

12. Rudan I, O'Brien KL, Nair H, Liu L, Theodoratou E, Qazi S, et al. Epidemiology and etiology of childhood pneumonia in 2010: Estimates of incidence, severe morbidity, mortality, underlying risk factors and causative pathogens for 192 countries. J Glob Health 2013;3:010401.

13. International Vaccine Access Centre. 2016 Pneumonia and Diarrhea Progress Report. Available from: http://www.jhsph.edu/research/centersand-institutes/ivac/resources/IVAC-2016-Pneumonia-Diarrhea-ProgressReport.pdf. [Last accessed on 2019 Jan 22].

14. UNICEF. UNICEF Data: Monitoring the Situation of Children and Women. Available from: https://www.data.unicef.org/topic/child-health/pneumonia. [Last accessed on 2019 Jan 22].

15. Child Survival and the SDGs. Available from: https://www.data.unicef.org/ topic/child-survival/child-survival-sdgs. [Last accessed on 2019 Jan 22].

Funding: None; Conflict of Interest: None Stated.

How to cite this article: Bashar MA. Introduction of pneumococcal conjugate vaccine in Universal Immunization Programme in India: A step toward realizing sustainable development goals. Indian J Child Health. 2019; 6(7):335-336.

Doi: 10.32677/IJCH.2019.v06.i07.001 